\title{
Internet Addiction and Antisocial Internet Behavior of Adolescents
}

\author{
Hing Keung Ma \\ Department of Education Studies, Hong Kong Baptist University, Hong Kong
}

Received 1 March 2011; Revised 27 June 2011; Accepted 17 August 2011

Academic Editor: Joav Merrick

Internet addiction and the moral implication of antisocial Internet behavior will be investigated in this paper. More and more people use the Internet in their daily life. Unfortunately the percentage of people who use the internet excessively also increases. The concept of Internet addiction or pathological use of Internet is discussed in detail, and the characteristics of Internet addicts are also delineated. The social (especially the antisocial) use of Internet is discussed. It is argued that the behavior of Internet use is similar to daily life social behavior. In other words, Internet behavior is a kind of social behavior. Kohlberg's theory of moral development is employed to delineate the moral reasoning of the antisocial Internet behavior. The following behaviors are regarded as antisocial Internet behavior: (1) the use of Internet to carry out illegal activities such as selling faked products or offensive pornographic materials, (2) the use of Internet to bully others (i.e., cyberbullying) such as distributing libelous statements against a certain person, (3) the use of Internet to cheat others, and (4) the use of Internet to do illegal gambling. The characteristics of the moral stages that are associated with these antisocial Internet behaviors are investigated in detail.

KEYWORDS: Chinese adolescents, Internet addiction, antisocial Internet problems, positive youth development, prevention 


\section{INTRODUCTION}

According to the survey by the Internet World Stats in 2005 [1], about $68.8 \%$ of the Hong Kong population, approximately 4.878 million people, are Internet users. Similarly, the Hong Kong Internet Project by City University [2, page 3] also found that "there were 3.65 million Internet users in Hong Kong at the end of 2008 , who account for $68.7 \%$ of the corresponding population (i.e., 5.31 million regular residents)" between the age of 18 and 74. The use of Internet becomes a daily activity for many people in Hong Kong, and Internet users usually regard Internet as important to their life, work, or study [2, page 21]. In some sense, Internet is an indispensable tool for many people. Unfortunately some people are overdependent on the Internet in their daily activities to the extent that the excessive use of the Internet causes damage and trouble in their daily life. In this paper, the prevalence of problematic Internet use will be discussed first, and the concept of Internet addiction will be delineated. The moral reasoning underlying the antisocial Internet behavior will also be discussed in detail.

The impact of Internet on our life becomes more and more significant and undeniable. Life without Internet is definitely very troublesome and inconvenient. The invention of Internet is just like the discovery of nuclear energy - it is the result of the rapid development of science and technology - it can be good or bad thing for human beings, depending on how we use it. It can be good if we use it prosocially or positively, and it can be bad if we use it immorally or antisocially. There is no simple way to stop science and technology development, but the teaching of a positive and moral attitude in the use of Internet is imminent and necessary in education nowadays.

\section{PATHOLOGICAL INTERNET USE OR INTERNET ADDICTION}

Some people spend a lot of time in Internet use every day, and their excessive Internet use has a significant and negative impact on their daily life. Some researchers regard this type of excessive Internet use as Internet addiction or pathological Internet use [3-11]. Internet addiction is usually regarded as an uncontrollable and damaging use of the Internet [12].

Shapira et al. [13, page 269] in their study on the psychiatric features of individuals with problematic Internet use found that problematic Internet use was "associated with subjective distress, considerable social, vocational, and/or financial impairments, as well as substantial psychiatric comorbidity." Based on previous research, three major concepts of Internet addiction are delineated as follows.

\subsection{Technological Addiction}

Internet addiction is regarded as a kind of technological addiction, which refers to "non-chemical (behavioral) addictions that involve human-machine interactions" [11, page 31].

Griffiths [7] argues that excessive Internet users may not be "Internet addicts" because they use the Internet excessively as a means to fuel their other addiction and interest. For example, compulsive gamblers use the Internet to gamble for a long time, or shopaholics spend long hours in the Internet for cybershopping.

\subsection{Categories of Internet Addiction}

Young [8-10] classifies Internet addiction into five different types of behaviors. (1) Cybersexual addiction: the addicts spent a lot of time in adult websites for cybersex and cyberporn. (2) Cyber-relationship addiction: the addicts involved heavily in online relationships. (3) Net compulsions: the addicts exhibited obsessive online gambling and shopping. They are compulsive online gamblers and shopaholics. (4) Information overload: the addicts displayed compulsive web surfing and database searches. (5) Computer game addiction: the addicts were obsessive online game players. 


\subsection{Pathological Internet Use}

Davis [5] prefers to use the term Pathological Internet Use (PIU) instead of Internet addiction. He focuses maladaptive cognitions associated with PIU and divides PIU into two categories: (1) Generalized PIU: it "involves a general, multidimensional overuse of the Internet. It might also include wasting time online without a clear objective" [5, page 188]. (2) Specific PIU: people with specific PIU are overdependent on a specific function of the Internet, for example, overuse of online sexual material/service, online auction services, and online gambling.

\subsection{The Concept of Internet Addiction}

In fact, there is no definition of Internet addiction that is universally accepted by psychologists and scholars in this field $[4,12]$. While the investigation of the concept of Internet addiction is still a main agenda of many researchers $[11,14]$, the problems of excessive use of Internet, especially in school students, become more and more prevalent and disturbing. It is perhaps useful and constructive to study carefully the typical behaviors of those who use the Internet excessively as well as what people are usually doing, prosocially or antisocially, in the Internet. The understanding of the nature of these problems may help researchers and educators to develop educational programs in solving some of these problems, for example, to promote positive use and to prevent antisocial use of the Internet.

\subsection{Prevention of Internet Addiction}

If Internet addiction is regarded as a kind of mental disorder [12], then the prevention of Internet addiction should become an essential part of a mental health program. It is believed that a holistic program that tries to provide a comprehensive and general basis for the development of a healthy body and mind is more effective than a specific program that focuses mainly on the problems associated with Internet use.

\section{CHARACTERISTICS OF INTERNET ADDICTS}

Shek et al. [15] examined Internet addiction behavior in 6,121 Chinese primary and secondary students in Hong Kong and found that one-fifth of their sample could be regarded as Internet addicted. Fu and his colleagues [16] found that $6.7 \%$ of the Hong Kong teenagers display five or more symptoms of Internet addiction. In addition, the Internet addiction symptoms seem to go along with individuals' suicidal ideation and depressive symptoms. The situation in China is also quite serious. About 13.7\% of adolescent Internet users (about 10 million teenagers) could be classified as Internet addicts [17]. The situation in Taiwan is also similar. Lin and Tsai [18] found that $11.8 \%$ of the senior secondary school students in their Taiwan study could be regarded as Internet dependents. Research also indicated that $4.0 \%$ to $8.1 \%$ of the university students showed excessive or pathological Internet use [19, 20].

The symptoms of Internet addiction or Pathological Internet Use include "obsessive thoughts about the Internet, tolerance, diminished impulse control, inability to cease using the Internet, and withdrawal" [5, page 187]. Beard and Wolf [21] have also proposed a set of diagnostic criteria for Internet addiction. The characteristics of Internet addicts are described below, with references to previous empirical studies.

\subsection{Excessive Use of Internet}

Internet addicts spend almost more than triple the number of hours in Internet use than non-Internet addicts [4]. Young also found that the average number of hours per week using Internet by Internet dependents was 38.5 hours, while the nondependents spent only an average of 4.90 hours [22]. According to a survey 
by Hong Kong Youths Association in 2005 [23], young people of ages 10 to 29 spent an average of 18.4 hours per week in Internet use. About one tenth (9.9\%) of the sample spent 42 hours per week, that is, an average of six hours per day on line. In some sense, Internet use is the most important or salient activity in the addicts' daily life, and they usually stay on line longer than they originally expected.

\subsection{Obsessive Thoughts about the Internet}

The addict "is preoccupied with the Internet (thinks about previous online activity or anticipates next online session)" [21, page 379] and is unable to refrain from thinking about the Internet most of the time when he or she is awake.

\subsection{Pleasant Feeling in Internet Use}

People have a lot fun by using Internet. The Internet exposures of the Internet addicts appear to be pleasurable, entertaining, interactive, and relaxed [24, 25]. Overall speaking, the addicts enjoyed the Internet experiences, and the enjoyment and pleasure would drive them to be addicted to Internet use.

\subsection{Tolerance}

The tolerance symptom refers to the "needs to use the Internet with increased amount of time in order to achieve satisfaction" [21, page 379]. This symptom is closely related to the excessive use or overuse of the Internet by the addicts.

\subsection{Diminished Impulse Control}

The diminished impulse control is related to the reduced emotional self-regulation to control one's impulses to reach a goal. In other words, the addicts tend to lose their control of their behavior. In particular, they are unable to cut back or stop Internet use.

\subsection{Withdrawal}

The withdrawal symptom of the addicts refers to the unpleasant feeling (restless, moody, depressed, or irritable) when the Internet activity is being stopped or cut down.

\subsection{Impact on Daily Life}

The impact on the daily life and study of the Internet addicts is usually negative [24]. The addicts may sometimes risk the loss of a significant relationship, educational or career opportunity because of the Internet. They may lie to others because of their overinvolvement with the Internet, and they also use Internet as a means to escape from problems or to settle one's unpleasant emotion such as helplessness, anxiety, guilt, or shame [21, page 379].

\subsection{Parental and Family Interactions}

Internet addicts spent less time with their parents and other family members and tended to have tension with them [22]. 
TABLE 1: Characteristics of Internet addicts.

\begin{tabular}{|c|c|}
\hline Characteristics & Typical Behaviours \\
\hline (1) Excessive use of Internet & Spent more than 40 hours on line per week. \\
\hline (2) Obsessive thought about the Internet & Unable to refrain from thinking about the Internet. \\
\hline (3) Pleasant feeling in Internet use & $\begin{array}{l}\text { Internet exposures are pleasurable, entertaining, interactive, and } \\
\text { relaxed. }\end{array}$ \\
\hline (4) Tolerance & $\begin{array}{l}\text { The need to use the Internet with increased amount of time in order to } \\
\text { achieve satisfaction. }\end{array}$ \\
\hline (5) Diminished impulse control & $\begin{array}{l}\text { Reduced emotional self-regulation to control one's impulses to reach } \\
\text { a goal; unable to stop using the Internet. }\end{array}$ \\
\hline (6) Withdrawal & $\begin{array}{l}\text { Unpleasant feeling when the Internet activity is being stopped or cut } \\
\text { down. }\end{array}$ \\
\hline (7) Impact on daily life & $\begin{array}{l}\text { Risking the loss of a significant relationship, educational or career } \\
\text { opportunity because of the Internet; lying to others, and escaping } \\
\text { from problems. }\end{array}$ \\
\hline (8) Parental and Family Interactions & $\begin{array}{l}\text { Spent less time with family members, the tension with parents is } \\
\text { usually high. }\end{array}$ \\
\hline (9) Friendship and romantic relationships & Less friends and romantic relationships. \\
\hline (10) Health problems & $\begin{array}{l}\text { Less willing to seek medical treatment and less motivated to develop } \\
\text { stress-relieving practices. }\end{array}$ \\
\hline (11) Academic performance & Usually at lower level. \\
\hline (12) Lonely character & $\begin{array}{l}\text { Lonely people used the Internet when they felt lonely, depressed or } \\
\text { anxious. }\end{array}$ \\
\hline
\end{tabular}

\subsection{Friendship and Romantic Relationships}

Internet addicts tend to have less friends and romantic relationships [26]. They are more lonely and solitary.

\subsection{Health Problems}

Internet addicts are less healthy than nonaddicts, and they are also less willing to seek medical treatment and less motivated to develop stress-relieving practices [26].

\subsection{Academic Performance}

Chang and Law [27] found that academic performance is negatively related to Internet addiction score.

\subsection{Lonely Character}

Morahan-Martin and Schumacher [28] found that loneliness is associated with increased Internet use. The average weekly hours on line of the lonely people was significantly higher than that of the nonlonely people. Lonely people used the Internet when they felt lonely, depressed, or anxious. "They were more likely to make and interact with online friends, and to use the Internet for emotional support" [28, page 669].

The characteristics of Internet Addicts are summarized in Table 1. 


\section{MORAL BASIS OF INTERNET USE}

Kohlberg [29-31] have proposed a six-stage theory of moral development. His first five stages are employed here to elaborate the underlying moral reasoning of prosocial and antisocial Internet use. According to Kohlberg [31], very few people reach Stage 6 which is a stage of Universal Ethical Principles. This stage will not be discussed here. For details of Stage 6, see Kohlberg [30, 31].

\subsection{Stage 1: Heteronomous Morality and Obedience to Authority}

People at this stage obey blindly what the authorities command in order to avoid punishment. In order words, if the adult does not allow them to use the Internet to bully others or to cheat others, then the children would think that it is not right to do so in the Internet.

\subsection{Stage 2: Individualism, Instrumental Purpose and Exchange}

People at this stage tend to act in their own self-interests. According to Kohlberg [30, page 148], the idea of equal exchange can be expressed by the following statement, "you should not hurt or interfere with me, and I should not hurt or interfere with you." The exchange in the cyber world is the same as that in the real world. If you hurt me in the cyber world, I would get revenge. Alternatively, if you do me a favor in the cyber world, I would also do you a favor.

The elaboration of individualism and instrumental purposes can be performed from the antisocial perspective. Children at this stage tend to take care of their personal interests and ignore other's interests. They are egocentric and do not play fairly and equally. They would cheat intentionally so long as they are not being caught. In the cyber world, a lot of misbehaviors and illegal activities are being conducted because the actors think that their identity is securely hid and may not be easily caught by the authority. In contrast to Stage 1 which places emphasis on obedience to authority in order to avoid punishment, this stage emphasizes on protecting one's personal interests by intentional cheating, unfair play, and acting illegally or unfairly without being caught by the authority. They would do anything to hurt others (e.g., cyberbullying, and infringement of other's privacy and intellectual property rights) in order to get what they want. The moral motivation underlying Stage 1 is blind obedience to authority but that underlying this stage is quite Machiavellian, that is, getting what you want by all means, including those illegal or improper means. In addition, "work is perceived as onerous. The good life is the easy life with lots of money and nice things" [32, page 17]. The idea is that one should try to get a lot just by paying little or no effort. Generally speaking, people at this stage claim as much rights as they can but tend to bear as little responsibilities as possible. In other words, they act or survive by the principle of opportunistic hedonism.

\subsection{Stage 3: Mutual Interpersonal Expectations, Relationships, and Interpersonal Conformity}

This is a stage of good-boy-nice-girl orientation. People at this stage would live up to what is expected by members of your primary group (e.g., family, school, religious or political parties) or people close to you. People in the cyber world also form a group or gang with common interests. They would be altruistic to their group members and would be willing to make sacrifices for their group members. On the other hand, they are less willing to help nongroup members in the same situation.

\subsection{Stage 4: Social System and Conscience}

The main concern is to uphold the social law and to carry out one's duty to maintain the social order. For example, illegal downloading, infringement of other people's copyrights, illegal online gambling and cyberbullying will be regarded as wrong and improper and not be allowed in the cyber world. It is also 
wrong for people to use high technology to attack government or big company's confidential data storage or computer system or even to disable, for example, the operation of transport, banking, communication, and military order in order to induce social disturbance and chaos.

\subsection{Stage 5: Social Contract or Utility and Individual Rights}

This is a stage of law-making in contrast to the Stage 4 which is a stage of law-abiding. In the elaboration of Stage 5, Kohlberg [33] refers to constitutional democracy and argues that it makes social law more attractive to a rational person because it puts one's basic rights prior to law and society. The laws and duties are based on "rational calculation of overall utility", "the greatest good for the greatest number" [34, page 35].

Apart from the general basic human rights that are being observed and complied at this stage, the personal data and privacy right are also emphasized. The development of high technology makes the leakage and abuse of personal data a common crime in the cyber world. The right for personal privacy, the right for an individual to lead a private and less open life should be fully respected and legally protected.

\section{ANTISOCIAL OR DELINQUENT INTERNET USE}

Based on previous research [35, 36], the major antisocial and delinquent behaviors of adolescents include (1) general deviance such as theft, alcohol use, cheating on exams, and coming to school late; (2) drug use; (3) defying parents (e.g., shouting at one's father or mother or going against your parents' wishes); (4) antisocial acts against one's teachers or school authority; (5) socially undesirable sexual activities; (6) aggressive or hostile acts such as bullying others or group fist fighting. It is argued that Internet behavior is a kind of social behavior. In fact, Ma et al. [37] have proposed the Positive Association Hypothesis which states that "There is a positive association between the Internet behavior and daily social behavior." In other words, positive Internet behavior is supposed to positively associated with positive daily social behavior, and negative Internet behavior is positively associated with negative daily social behavior. Their data involving 509 secondary school students clearly supported the hypothesis. The implication of this study is that the cyber world is not virtual, it is quite real-it is in fact part of our real world. Educationally speaking, we should place more emphasis on Internet use education because of the prevalence and popularity of Internet use in young people.

The following behaviors are regarded as antisocial Internet behavior.

\section{(1) Illegal Downloading}

Downloading film, music or video clips without permission is a common illegal activity that adolescents carry out in the Internet. In a survey of 559 young people of age 10 to 24 on Internet activities, 57.4\% of the participants admitted that they had downloaded film or music without obtaining permission from the license holders [38].

\section{(2) Pornographic or Aggressive Information}

In the same survey, $37.9 \%$ of the participants indicated that they have obtained pornographic or obscene or aggressive materials through the Internet [38].

\section{(3) Cyberbullying}

It is the use of Internet to bully others (i.e., cyberbullying) such as distributing libelous statements against a certain person; humiliating, embarrassing, or harassing the peers: About $40 \%$ of the teens indicated that they have been bullied while they were on-line $[39,40]$. 


\section{(4) Cheating Behaviour}

It is the use of Internet to cheat others. It is easy to cheat others on line because you are anonymous to others and your identity can be hidden easily if you wish.

\section{(5) Online Gambling}

You can gamble online with others or take part in the online casinos. Online gambling includes online poker, online sports betting, online lotteries, and online bingo [41].

In addition, some adolescents may also use the Internet to carry out illegal activities such as selling faked products or offensive pornographic materials or to carry out morally or socially unacceptable activities such as compensated dating.

The judgment of each of the above Internet behaviors can be explained by Kohlberg's [30, 31] stages of moral development presented in the above section, "Moral Basis of Internet Use". Ma [42] argued that moral judgment is an essential component of moral competence which is one of the 15 positive youth development constructs proposed by Catalano and his colleagues [43]. The moral basis of Internet use thus also depicts a strong association between the moral competence and Internet behavior.

\section{PREVENTION OF ANTISOCIAL INTERNET USE}

Generally speaking, a holistic program that was based on positive youth constructs [43] or positive moral characters [44] would be helpful to promote prosocial Internet use and prevent antisocial Internet use. Specifically the program should place emphasis on the following constructs or characters: (1) self-respect or self-esteem, (2) respect for others, (3) social and civil responsibility, and (4) global responsibility and world citizenship. In addition, the teaching of self-efficacy, time management, self-discipline, or self-control is also useful in cultivating a positive attitude in the use of Internet. The rationale for developing a teaching program for junior secondary students is given in Ma and his colleagues [45].

\section{CONCLUSIVE REMARKS}

More and more people use the Internet in their daily life. Unfortunately the percentage of people who use the Internet excessively also increases. The concept of Internet addiction or pathological use of Internet is discussed in detail, and the characteristics of Internet addicts are also delineated. The antisocial use of Internet is also discussed. It is argued that the teaching of a positive and moral attitude in the use of Internet should become an indispensable part of our education nowadays. It is also believed that a general, holistic, whole-person education program that is based on Catalano et al.'s [43] positive youth constructs and Ma's [44] positive moral characters is effective for promoting prosocial Internet use and preventing antisocial Internet use.

\section{ACKNOWLEDGMENT}

This research was supported by Hong Kong Jockey Club Charities Trust.

\section{REFERENCES}

[1] Internet World Stats, "Hong Kong: internet usage stats and market report," 2010, http://www.internetworldstats .com/asia/hk.htm.

[2] Hong Kong Internet Project, "Internet use in Hong Kong: the 2008 annual survey report," Web Mining Lab, Department of Media \& Communication, City University of Hong Kong, 2009, http://newmedia.cityu.edu.hk/ hkip/. 
[3] S. E. Caplan, "Problematic internet use and psychosocial well-being: development of a theory-based cognitivebehavioral measurement instrument," Computers in Human Behavior, vol. 18, no. 5, pp. 553-575, 2002.

[4] C. Chou and M. C. Hsiao, "Internet addiction, usage, gratification, and pleasure experience: the Taiwan college students' case," Computers \& Education, vol. 35, no. 1, pp. 65-80, 2000.

[5] R. A. Davis, "Cognitive-behavioral model of pathological Internet use," Computers in Human Behavior, vol. 17, no. 2 , pp. 187-195, 2001.

[6] I. Goldberg, "Internet addictive disorder (IAD) diagnostic criteria," 1997, http://www.psycom.net/iadcriteria .html.

[7] M. Griffiths, "Does internet and computer "addiction" exist? Some case study evidence," Cyberpsychology \& Behavior, vol. 3, no. 2, pp. 211-218, 2000.

[8] K. Young, "Internet addiction: the emergence of a new clinical disorder," in Proceedings of the 104th Annual Meeting of the American Psychological Association, Toronto, Canada, August 1996.

[9] K. Young, "Internet addiction: the emergence of a new clinical disorder," Cyber Psychology \& Behavior, vol. 1, pp. 237-244, 1998.

[10] K. Young, "Internet addiction: symptom, evaluation, and treatment," in Innovations in Clinical Practice: A Source Book, L. VandeCreek and T. L. Jackson, Eds., vol. 17, pp. 19-31, Professional Resources, Sarasota, Fla, USA, 1999.

[11] L. Widyanto and M. Griffiths, ““'Internet addiction”: a critical review,” International Journal of Mental Health and Addiction, vol. 4, no. 1, pp. 31-51, 2006.

[12] K. W. Beard, "Internet addiction: a review of current assessment techniques and potential assessment questions," Cyberpsychology \& Behavior, vol. 8, no. 1, pp. 7-14, 2005.

[13] N. A. Shapira, T. D. Goldsmith, P. E. Keck Jr., U. M. Khosla, and S. L. McElroy, "Psychiatric features of individuals with problematic internet use," Journal of Affective Disorders, vol. 57, no. 1-3, pp. 267-272, 2000.

[14] A. Blaszczynski, "Internet use: in search of an addiction," International Journal of Mental Health and Addiction, vol. 4, pp. 7-9, 2006.

[15] D. T. L. Shek, V. M. Y. Tang, and C. Y. Lo, "Internet addiction in Chinese adolescents in Hong Kong: assessment, profiles, and psychosocial correlates," TheScientificWorldJournal, vol. 8, pp. 776-787, 2008.

[16] K. W. Fu, W. S. C. Chan, P. W. C. Wong, and P. S. F. Yip, "Internet addiction: prevalence, discriminant validity and correlates among adolescents in Hong Kong," British Journal of Psychiatry, vol. 196, no. 6, pp. 486-492, 2010.

[17] J. J. Block, "Issues for DSM-V: internet addiction," American Journal of Psychiatry, vol. 165, no. 3, pp. 306-307, 2008.

[18] S. S. J. Lin and C. C. Tsai, "Sensation seeking and internet dependence of Taiwanese high school adolescents," Computers in Human Behavior, vol. 18, no. 4, pp. 411-426, 2002.

[19] J. Morahan-Martin and P. Schumacher, "Incidence and correlates of pathological internet use among college students," Computers in Human Behavior, vol. 16, no. 1, pp. 13-29, 2000.

[20] W. Wang, "Internet dependency and psychosocial maturity among college students," International Journal of Human Computer Studies, vol. 55, no. 6, pp. 919-938, 2001.

[21] K. W. Beard and E. M. Wolf, "Modification in the proposed diagnostic criteria for Internet addiction," Cyberpsychology \& Behavior, vol. 4, no. 3, pp. 377-383, 2001.

[22] K. S. Young, "Internet addiction: a new clinical phenomenon and its consequences," American Behavioral Scientist, vol. 48, no. 4, pp. 402-415, 2004.

[23] Hong Kong Youths Association, "Youth opinion survey: the main Internet activities and hidden problems of youths" (Chinese), 2005, http://www.hkfyg.org.hk/chi/press_releases/2005/research/internet.html.

[24] C. Chou, J. Chou, and N. N. Tyan, "An exploratory study of internet addiction, usage, and communication pleasure-the Taiwan's case," International Journal of Educational Communications, vol. 5, no. 1, pp. 47-64, 1999.

[25] D. McQuail, "Communication theory: uses and gratifications," 1994, http://en.wikibooks.org/wiki/ Communication_Theory/Uses_and_Gratifications.

[26] K. Bryan, "Teens with Internet addiction. Fyi living," 2010, http://fyiliving.com/depression/health-in-teens-withinternet-addiction/. 
[27] M. K. Chang and S. P. M. Law, "Factor structure for young's internet addiction test: a confirmatory study," Computers in Human Behavior, vol. 24, no. 6, pp. 2597-2619, 2008.

[28] J. Morahan-Martin and P. Schumacher, "Loneliness and social uses of the internet," Computers in Human Behavior, vol. 19, no. 6, pp. 659-671, 2003.

[29] L. Kohlberg, "Stage and sequence: The cognitive developmental approach to socialization," in Handbook of Socialization Theory and Research, D. Goslin, Ed., pp. 347-480, Rand McNally, Chicago, Illionios, USA, 1969.

[30] L. Kohlberg, Essays on Moral Development, vol. 1 of The Philosophy of Moral Development, Harper \& Row, San Francisco, Calif, USA, 1981.

[31] L. Kohlberg, Essays on Moral Development, vol. 2 of The Psychology of Moral Development, Harper \& Row, San Francisco, Calif, USA, 1984.

[32] J. Loevinger, Ego Development: Conceptions and Theories, Jossey-Bass, San Francisco, Calif, USA, 1976.

[33] L. Kohlberg, "From is to ought: how to commit the naturalistic fallacy and get away with it in the study of moral development," in Cognitive Development and Epistemology, T. Mischel, Ed., pp. 151-284, Academic Press, New York, NY, USA, 1971.

[34] L. Kohlberg, "Moral stage and moralization: the cognitive-developmental approach," in Moral Development and Behavior, T. Lickona, Ed., pp. 31-53, Holt, Rinehart and Winston, New York, NY, USA, 1976.

[35] H. K. Ma, D. T. L. Shek, P. C. Cheung, and R. Y. P. Lee, "The relation of prosocial and antisocial behavior to personality and peer relationships of Hong Kong Chinese adolescents," Journal of Genetic Psychology, vol. 157, no. 3, pp. 255-266, 1996.

[36] M. J. Hindelang, T. Hirschi, and J. G. Weis, Measuring Delinquency, Sage, Beverly Hills, Calif, USA, 1981.

[37] H. K. Ma, S. C. Li, and J. W. C. Pow, "The relation of Internet use to prosocial and antisocial behaviour in Chinese adolescents," Cyberpsychology, Behavior, and Social Networking, vol. 14, no. 3, pp. 123-130, 2011.

[38] Hong Kong Youths Association, "Youth opinion survey: what is wrong in the internet use of youths?" (Chinese), 2009, http://www.hkfyg.org.hk/chi/press_releases/2009/research/internet.html.

[39] I-Safe, "Cyberbullying: statistics and tips," 2010, http://www.isafe.org/channels/sub.php?ch=op\&sub_id=media_ cyber_bullying.

[40] Wikipedia, "Cyberbullying," 2010, http://en.wikipedia.org/wiki/Cyber-bullying.

[41] Wikipedia, "Online gambling," 2010, http://en.wikipedia.org/wiki/Online_gambling.

[42] H. K. Ma, "Moral competence as a positive youth development construct: conceptual bases and implications for curriculum development," International Journal of Adolescent Medicine and Health, vol. 18, no. 3, pp. 371-378, 2006.

[43] R. F. Catalano, M. L. Berglund, J. A. M. Ryan, H. S. Lonczak, and J. D. Hawkins, "Positive youth development in the United States: research findings on evaluations of positive youth development programs," Annals of the American Academy of Political and Social Science, vol. 591, pp. 98-124, 2004.

[44] H. K. Ma, "Moral development and moral education: an integrated approach," Educational Research Journal, vol. 24, no. 2, pp. 293-326, 2009.

[45] H. K. Ma, W. Y. Chan, and K. Y. Chu, 'Construction of a teaching package on promoting prosocial Internet use and preventing antisocial Internet use,” this issue, 2011.

\section{This article should be cited as follows:}

Hing Keung Ma , "Internet Addiction and Antisocial Internet Behavior of Adolescents," TheScientificWorldJOURNAL, vol. 11, pp. 2187-2196, 2011. 